\title{
A Qualitative Study of Mothers Who Work Full-Time as Hospital Floor Nurses
}

\author{
Michael Firmin ${ }^{1}$, Megan Bailey Pathammavong ${ }^{2}$ \\ ${ }^{1}$ Cedarville University \\ E-mail: firmin@cedarville.edu \\ ${ }^{2}$ Lipscomb University \\ E-mail: megancbailey@gmail.com
}

\begin{abstract}
We conducted qualitative interviews with a sample of 13 female floor nurses in a Midwest hospital. The women worked full-time and also had children at home for whom they provided care. The overall four results include particular challenges they faced in their dual-roles, including separating home from work, high stress, sleep deprivation, odd hours, and difficulty in advancing due to home life pressures. The nurses also related perceived assets and drawbacks of their profession for the given season of life. They described what they believed to be necessities for success in the dual-roles of professional nurse and care taker. Last, they related two wish-list components they desired at this point their careers as they engaged in child rearing.
\end{abstract}

Keywords: Nursing; working mothers; stress; floor nurses; qualitative research.

\section{Introduction}

Demographics indicate that the number of women with young children who have joined the work force has increased from $44 \%$ to $71 \%$ in the past 30 years [1]. Hayes, Bonner, and Pryor [2] report that many of these mothers who are working outside the home have children under 12 months of age. Researchers have given particular focus to the effects that working full-time has on children [3], children's relationships within the family of a full-time working mother, children's temperament and the mother's work functioning [4], inter-role conflict [5], and the effects of child rearing on the working mother's wages [1]. 
Much of the reported research in the literature focuses on the benefits of working mothers [6]. Galinsky [7] found that $81 \%$ of 13-18 year olds believed working mothers can have as good a relationship with their children as do stay-at-home mothers. Also, $77 \%$ of 8-18 year olds in Galinsky's sample did not believe that working mothers were more concerned about being successful in their careers than they were about taking care of their children's needs. Generally, Galinsky found that, especially when both parents are involved, employment of mothers outside of the home does not, per se, negatively affect children.

Some research reports liabilities of working mothers, however (e.g., Hyde [3]). Barglow, Vaughn, and Molitor [8] found that $31 \%$ of infants with working mothers were classified as having insecure-avoidant attachment and $54 \%$ were classified as having secure attachment. In contrast, 9\% of infants of non-working mothers were classified as insecure-avoidant and $71 \%$ as secure. Similarly, child care, other than that given by the mother, can have some negative effects [9]. In sum, potential risks may exist for some children of working women.

Research suggests particular hardships are experienced by women employed as nurses, especially when they have children at home [10] [11]. Barnett and Marshall [12] described the nursing profession as a high-stress occupation, with high job demand and low job control. Letvak [13] emphasized the pressures that nurses particularly encounter, such as long and irregular hours, staff shortages, downsizing, and the like. Williams [14] described a campaign to help nurses balance work and home life, noting that some nurses have to quit their jobs because they find it impossible to balance both of these roles. Garey [15] [16] explained how that many nurses with children at home work the night-shift or part-time in order to remain at home with their children during the day. Rich, LePine, \& Crawford [17] described various dissatisfactions with working conditions among nurses who have young children.

Given the potential stresses involved with full-time working mothers, needs exist regarding a better understanding of what motivates them to engage and develop their careers. In particular, we conducted the present study in order to engage the question regarding why some mothers choose highly stressful jobs, such as nursing. While nursing positions possess both benefits and liabilities, relatively little is known from the current research literature regarding how nurses maintain professional and personal equilibrium with these life presses. The present research study addresses these important issues in the context of how caretaking competes with care giving.

\section{Method}

\subsection{Participants}

A sample of 13 female nurses was selected for study in a Midwest hospital. Criterion sampling was used as each person had at least one child living in the 
home (generally, 18-years-old or younger). The women worked full-time, defined as 36 hours per week, which is considered full-time employment at this hospital. The nurses also held jobs in similar work environments to one another relative to general stress-levels, such as OB and oncology. We purposefully did not include in our sample nurses working in positions that generally are considered particularly high stress milieu, such as the emergency room. The women in this study were floor nurses, meaning that they had personal interaction with the patients and were responsible for the direct care of the patients. Ten of the floor nurses were married, two were divorced, and one identified herself as "other." The number of children at home ranged from one to four, with the majority having two children. One of the floor nurses was an LPN, three obtained their diplomas, three had obtained an associate's degree as their highest level of education, and six possessed the BSN degree. Specific age demographic data is not reported here due to ethical agreements with the participants of assuring their complete anonymity (per IRB approval). The nurses generally were in the 30 to 40 year old age range and all were White (Caucasian).

\subsection{Procedure}

Interviews were tape recorded and later transcribed for analysis. Coding strategies followed Maxwell's [18] protocol whereby we formulated motifs from the narratives based on our semi-structured interviews. The emphasis in the interview process was allowing the participants to tell their own stories. As such, our roles in data collection were viewed in terms of giving voice to the views of the floor nurses [19]. Neither of the project's authors have been or presently work as nurses. Consequently, this provided a degree of objectivity to the data collection process. Obviously, complete neutrality is impossible; nonetheless, Bogdan and Biklen [20] suggest that research conducted by "outsiders" has advantages in qualitative inquiry-including being less likely to fish for preconceived perspectives from participants. Similarly, neither of the authors are mothers.

Constant comparison among the interview transcripts provided the basis for applying open-coding strategies [21]. As such, we did not approach the study with a predetermined set of percepts that we expected to find; rather, the process was inductive (i.e., open). We assessed the data for themes, generating outlines and collapsed categories of similar constructs where feasible. In some cases, overlapping categories existed, so these were compared with similar findings in terms of both key words/phrases and continuity of ideas being communicated by the participants. In the end, we believed the reflexive analysis allowed for a rich insight and an apt basis for further data appraisal [22].

We discarded some potential themes where insufficient data existed to support our initial hypotheses. We included themes in the final draft only when consensus existed among each of the participants. Both researchers assessed the transcripts, 
providing a level of bi-comparison and checks for internal validity in coding and theme generation [23]. Regular meetings between the co-authors helped to provide natural points of appraisal and evaluation of the conclusions being drawn from the data.

Support for conclusions also was garnered through personal observations in the hospital setting. Although this is a phenomenological rather than ethnography study, our findings do nonetheless reflect some of our field notes taken as we observed the nurses in their work environments. Overall, conclusions were generated via an inductive method as we were interested in drawing the existing conclusions from the data rather than superimposing the data with an existing paradigm(s). In this sense, we engaged in exploratory research. Member checking occurred among various participants after themes were generated in order to provide an added layer of checks for internal validity [24]. The pseudonyms used in this article for reading clarity are fictitious.

Internal validity for the study was also enhanced through independent expert review [25], generating a data audit [26], and obtaining saturation in the data collection process [21]. The review was provided by an expert in qualitative research who was not involved in the data collection or analysis portion of the study. He examined the data trail and provided input regarding the sufficiency of grounded conclusions and authenticity of findings presented in the present study. Saturation began occurring after the tenth interview. Consequently, we collected a few additional interviews in order to assure that no new potential findings were being generated from the interviews and data collection was discontinued at that point.

We genuinely respect researchers with applied theoretical orientations to the qualitative method. However, our own paradigm is in Glaser's [28] more traditional approach, as applied to both grounded theory and phenomenological research paradigms [29]. We do not debate the issue here, only explicitly inform the reader that the approach we take is a legitimate one in qualitative traditions and we believe to be the most apt for the present endeavor. Consequently, we did not have a guided theory in developing constructs and deliberately there is no theoretical orientation in our discussion section of the article. It is not an overlooked element but, rather, we believe it to be a strength of the research design and report. This matter has been debated since Glaser and Strauss [30] first generated their seminal work in grounded theory [31] and the matter likely will not be settled in the relatively near future [32]. In short, our present study is an inductive, qualitative approach to the topic being studied. 


\section{Results}

\subsection{The Challenges}

\subsubsection{Balancing}

Most of the women expressed the same challenge they face as working mothers, balancing between their two roles of professional and care giver to their children. For example, when asked what particular challenges she faced, Lisa stated: "Trying to coordinate everything, work, family, home..." Nursing jobs in hospital settings often involves working more extended shifts, compared to bankers hours of other typical first shift jobs. Karen explained her particular challenge in this respect: "Being able to find some quality time with my kids... I work ten and a half hours, go home, do the mom thing, run my kids around and there's just not any time left in my day." Similarly, Susan stated: "Being there for the kids all the time... You miss a lot, just because you're not there."

Naturally, the working nurse mothers in our study are not ubiquitous. They are limited by both time and space which was said to be a particular challenge for success in both home and hospital settings. Sarah expressed the time challenge she faces as an inability to be omnipresent: "Having enough time to do everything. We can't be everywhere, you have kids in after school activities and such, it's hard to get all that done, be where you need to be..." Likewise, Julia said her biggest challenge is "time management, trying to make time for your family, and workloads and extracurricular activities and things. I just try to keep a good balance...But it can be stressful." The women in our sample described feeling as though their jobs and their family responsibilities were "full time" expectations. As such, it takes particular skill and effort to successfully balance these two domains. Explaining the two areas in which she is "full-time," Melanie indicated her biggest challenge is "home management. Struggling with a full time job and....in my opinion, I'm a full time mother, a full time nurse and full time homemaker; I do it all. Time management is the hardest thing, just learning to work it all together."

\subsubsection{Separating work and home}

Another challenge these women face, particularly in their profession, is keeping their home life and their work life separate. While life exists on a holistic plane, the mothers described themselves as striving to keep their work lives and home lives from fusing. Ann explained:

Even though you're supposed to leave your problems at the doorstep, whether you're walking home or walking to work, it's very difficult; if you have a hard, physical, mentally challenging day at work, it's hard to not go home and not have some of those, you know, roll over into whatever. Same thing if you get up and your kids were up all night long for whatever reason, you know, 
and you're tired physically from that, or emotionally, it rolls over into your work, so I think it is difficult.

Nurses are trained professionally to compartmentalize their personal lives. While this phenomenon would be beneficial in many ways emotionally, nurses struggle actually making it happen on the application level. Lisa expressed her challenges in this regard:

I guess between, you know, leaving work and going home...[to] make that switch over from work to home so you can sort of leave your work behind...between patients, family, physicians, trying to balance all that. I guess it's just dealing with that at work and then being able to leave that at work when you go home....I'm sure that there's times that something happens at work and then you take that home... and then you probably come in here and then you're use to being a mother and, you know, sometimes you're taking care of patients that are the ages of your kids or, you know, then it's like you want to take on more of this mother role where it needs to be more of a nurse patient....

Separating personal from professional lives can be difficult for all nurses, but perhaps particularly so for mothers during specific developmental stages. The season of life where developing professionals also are rearing children seemingly can be particularly challenging. Susan described her own particular challenge in being a mother of an infant while working in O.B.:

I try not to take things home with me, that happened at work, but there are certain occasions or certain situations that you do and, especially with having a baby, you know, I don't know if you know what a fetal demise is, or a still born, but that's probably one of the hardest and most stressful situations that we deal with here and that's something that I do tend to take home with me because it's hard for me to get over that... I try to leave the stress here because there's times, if I do take it home, I can tell that if I'm worked up, you know, my husband and I don't get along like we should. So I do try to leave it here, but it is hard sometimes... So, I don't know, I just try to deal with it here as much as I can so I don't take it home.

Although a nurse's job primarily involves accomplishing particular tasks, there are emotional aspects of the work. Turning on/off feelings in a work/home milieu can be a special challenge. While nobody can accomplish this feat entirely, the attempt is made by nurses who are also mothers. As an example, Monica related her difficulty of keeping work in O.B. and home separate:

The most important thing is that you don't want to take it home to your family and I think it's impossible and it would be a lie if I told you I never had. You know, you go home if you have a bad day, number one just an extremely busy day that's stressful and frustrating. But in nursing a lot of times you have really, really bad days for other reasons, especially in OB; OB 
is $90 \%$ of the time a very happy place to work, but when it's sad it's extremely, extremely sad and it's very, very hard not to take that home to a certain degree...you get close to the patients and, like I said, it's very, very sad back here and it's hard not to take that home with you when you have a fetal demise or even just a baby that's not born exactly perfect... But it's hard not to be really depressed and sometimes angry when you go home. It's just hard not to be in a bad mood and snap at the kids or something.

\subsubsection{High stress, demand, and responsibility}

The women expressed that they find stress, demand, and responsibility to be particularly high when working the floor. Obviously, few professional jobs are stress free. Nonetheless, the nurses in our sample described their nursing responsibilities to be a notch above what they considered to be typical job strain. Karen related the sentiments of most participants in this regard when she explained the importance of what she does and the stress because of it:

I think the stress, the stressors that are unique to nursing, just, you know, having to be really good at what you do and be paying attention, being, you know, a liaison... trying to be really good at what you do and keep everybody happy and everybody safe and... that's enough stress to really make you tired at the end of the day and cranky and not wanting to do anything else except go home...you kind of have to be real particular to be in the nursing and medical field. And I really don't think it's enough [money paid] for what you do, what you have to know and how important your job is and the big picture... nursing is just high tech, high stress, a very demanding, demanding field.

Certainly other occupations also involve pressure as part of the normal daily work routine. Nursing, however, does appear to possess some unique dynamics. Some of these elements surfaced in the data provided in the interviews. For example, Rachel noted the difference between a career in nursing and other careers:

There's a lot of responsibility with nursing, but I think there may not...you wouldn't maybe find that in another job because we are responsible for the safety of our patients and medication and if, you know, if they're sick or the jobs we do... we have to make sure that they're stable, that kind of thing. A lot of caretaking, a lot of, also taking care of the family, making sure the patients know what to do and the family knows what to do when they go home. Sometimes you get into a situation where things aren't just, you know, set up right and so then you have to go into more detail to make sure the patient's going to be safe at home...different things, consulting home health, that kind of thing.... Whereas maybe other jobs don't have that stress at work....

The nurses in our sample did not indicated, however, that they were surprised by the demands of their jobs. Evidently, they knew going into their careers that 
nursing would be rigorous. For example, Mary summarized what other nurse mothers warned her: "I always knew that nursing is a stressful job... I had heard from other nurses that being a mom and being a nurse can be pretty taxing."

\subsubsection{Lack of sleep/irritable}

All of the previously mentioned challenges often lead to this next challenge: lack of sleep and irritability. Sleep deprivation studies clearly have shown that such states take significant temporary tolls on people's psychological well being. It is difficult to experience work efficiency — or to enjoy one's job optimally-when regularly sleep deprived. Karen illustrated much of what we heard during interviews when she told of her own recent situation:

I was accused of being a Nazi the other day! I've been a single mom a long time, too, and with four kids I only have time and energy to tell you once and the second [time] I have to tell you, you're going to know you've been told. Where at home everything's organized; at home, you know, I tend to be a little more authoritative and other mothers are more cuddly. But it's...I think my fiancé asked me one time, 'are all nurses bossy?' To some degree, yeah, especially if you work in a place like this; in a doctor's office or something it might be different. But yeah, you know, you got a lot of people on different schedules, gotta go, gotta go, gotta go. You don't have time to sit around, you don't have time; I always try to be pleasant, but there are sometimes when you just say I'm in charge today.

Rachel similarly described a situation she experienced in the shift she worked previously:

There was a lot of time that you would be up all night and then the next day, it was like regulating yourself between days and nights on your days off, so sometimes you would be up 24 plus hours and that didn't feel good; a lot of times I didn't feel good!

As previously mentioned, stages of life are a dynamic that seems to affect nurses' work experiences. Post-partum is one such phase that was noted by most individuals in our sample. While they appreciate family leave, returning to work becomes inevitable and a new level of tension evidently begins. Nichole illustrated this fact when explaining how difficult it was for her after having her baby:

When I first came back to work [after having her daughter] I didn't do very well with dealing with stress. And I think it was just being a new mom, um, working 12 hour shifts, having a new baby, not getting enough sleep, just everything, just rolled up into one.

Mary provided an apt summary that seemed to express the sentiments of most floor nurses on this point. Sleep deprivation was not said to cause difficulties, per se, but it did add a stress dynamic that all noted in their respective interviews. 
The early child-rearing years, in particular, were said to be especially taxing at the physical level:

Lack of sleep if you work full time. You know, the kids are up in the middle of the night and you've got to work the next day. Coming home and then, you work all day and then you have to come home and make sure dinner's ready and get them ready for the next day, get them bathed, get them fed.... guess like when you come home from a nursing job, you know, you're constantly on your feet, you're constantly on the go and you get home and you really don't have time to rest....because you've got a two year old running around at home! So, that's, I mean, that's one of the big things I think. You don't really get a break when you get home; I mean you get used to it, but....like I said, it just... basically can be tiring.

\subsubsection{Odd hours/on call/work weekends}

Most of the nurses expressed that the challenge of odd hours, being on call, and working weekends was a unique, stressful cocktail that made their profession to be particularly challenging. Often these dynamics appear to be somewhat of unwritten norms for floor nurses. That is, the employee handbook does not necessarily mandate some of the paid or unpaid overtime but, rather, the nurses feel an internal ethical obligation I order to ensure that their jobs are well done. This dynamic may extend to multiple aspects of patient care. With finite hours in each day, it was said to contribute to family stress at times. Rachel explained:

The hours are not exactly 8-4:30, sometimes we can't leave at 4:30 just because it's 4:30. If we have a patient that's ill or...we can't just walk out. We do holidays, a lot of places don't, we take call here so... a lot of, I think, jobs don't do that. So...again I think getting off those actual hours are different than other jobs. And along that line, too, we also don't always get all of our hours either because, if all the patients go home a couple of hours early, then we go home a couple hours early also; we aren't allowed to stay here if there's no patients. I miss, my daughter plays soccer in high school; I missed most all of her games this past year because I got off too late. I'm hoping next year to try and maybe make some kind of changes, if possible, so I could get off. It's hard to try and have some kind of a nice dinner for the kids when I don't get home until after, you know, after they've probably already eaten....

Julia similarly noted that, it not only is the amount of hours worked that can cause stress, but also the shift times. Floor nurses do not always enjoy bankers' hours: "I would probably say the hours; the difficult hours that I work, from $3 \mathrm{pm}$ to 3 am. It just kind of leaves little time to actually be with your family and do things outside of work." Mary agreed and also added the dimension of missing holidays:

When I first started nursing, I think I was in nursing 12 years before I ever spent a Christmas with my kids. I never saw a holiday with them, never, and 
there's always that sort of obligation where somebody called in...on a holiday and they were short, so I worked.

We note that the nurses in our sample were reasonable individuals. That is, they understand the duty of their professional calling and patient sickness does not take a hiatus for the holiday season-care is needed year round. Nonetheless, the accumulation of missed holidays, over time, becomes taxing. Lisa provided the following summary that captured the sentiments of most nurses in the study on this point: "I think the hours that we work, the weekends, holidays....being on call and having to be called in or, you know, being scheduled to work and being called off....that sort of thing I think probably is sort of unique in our profession."

\subsubsection{Hard to advance}

Another challenge that seemed to be especially difficult for the women in our example is the challenge in trying to professionally advance, particularly because of having family responsibilities. Sarah, for example, knew it would require an advanced degree in order for her to achieve promotion and she stated some of her limitations in this regards: "I don't know how people go to school and have kids, I can't do it." Lisa agreed that going back to school and/or advancing professionally would be difficult for her situation, given her current season of life:

As far as being a working mother it might make it harder as far as, you know, additional education, that sort of thing. Again, being able to combine or manage, you know, a home and work and the kids, so I mean, it's just a little bit more of a challenge....

Monica related this point as being more than just challenging; rather, she stated plainly: "I can't work full time and go to school and still be a mom. I just wouldn't have the time for them." Also, when asked what she would do differently if she could go back she stated:

If I could go back and make them, I would've furthered my education before I had kids. I would've gone ahead and gotten it at the time. The reason I didn't was right at that point I was engaged and I got the degree that I got and thought, well I'll go back later. When you first get married there's no money, you don't go back to school, there's no money to do anything. And then by the time there was money, then we were having children and then I didn't want to go back then because I thought it would take away from the mom aspects. It was working and going to school and studying, I wouldn't have had time with my kids. And that's been for the last 20 years, that's been my excuse, my reason, because of the kids. So I think if I would've gone ahead and just taken the degree farther at that time it would've been a lot better...But I think that would've been a very wise decision to make; hindsight's 20/20.

While the need for further education was common among many of the study's participants, it was not noted by all. Rather, all nurses commonly stated the 
general principle that advancement in their jobs was the challenging key principle (for a variety of reasons). They did not speak in terms of impossible advance, just some pause given due to the personal costs and their due deliberations given before making whatever commitments would be required in order to advance. For example, Julia believes the opportunity to advance exists, but the decision is a personal choice with both rewards and potential costs:

I think there's always opportunity for advancement but I guess it just depends on how much more time you are wanting to dedicate to your job and time away from your family that you're willing to give up. For me right now, I think family means more to me right now maybe because I'm a little bit younger and I have a newer family, but there's always opportunity for growth.

\subsection{The Assets}

Although the research participants related six challenges to being nurses who also were mothers, the interviews were not all gloom-and-doom in sentiment. Rather, the nurses provided a reasonably objective perspective of how reality existed for them. In addition to the perceived encumbering matters noted, the mothers also related some identified benefits of being nurses who were working mothers. In particular, they related six elements of their jobs that they framed as potential life assets.

\subsubsection{Personal fulfillment}

Although there are many challenges these woman face as nurses, their profession also provides numerous rewards. One of the greatest benefits these nurses expressed was that of personal satisfaction. Ann explained: "Personal fulfillment...I get a lot of fulfillment, you know, from my job, doing this job...I feel very fortunate that I actually feel fulfilled with the job that I have and actually, for the most part, enjoy coming to work." Similarly, Karen stated: "I get a lot of kicks out of it most of the time...intrinsic, a feeling of accomplishment, I think, is the biggest reward we get and that comes from within..." Each of the nurses in our sample, unanimously related the notion of personal satisfaction in their respective jobs, each sharing their respective sentiments in various ways. Nichole related her specific experience working in OB.:

I guess it makes me feel good that I can come in and help people. And having a baby is a joy in everyone's life and I just, I like being a part of that and I like helping with the mom-to-be and the dad-to-be, you know, going through that. And all the doctors that I work with, I have a very good report with them and the people that I work with, I feel like, you know, I work well with them and you know, that just makes me feel good, knowing that I have a good relationship with the people that I work with, nurses and doctors, and you know extra staff members. So, it just, it makes me feel good that I'm helping someone, you know, and helping bringing that baby into the world. And if the 
baby, with working in special care nursery and working with the preemies, it's always nice to see that joy in the parents' faces if, you know, the baby's taking so much of the feeding and, you know, is gaining weight and we're helping. I'm helping that baby to do all those things and just to see the excitement in the parents eyes and it's really fulfilling to me.

It is difficult to capture pathos, at times, in the participants' interviews. Overall, the nurses' facial expressions, tone, and body language communicated genuine excitement when they spoke of their nursing roles. Melanie explained how she always wanted to be a nurse: "I chose this position...I always knew I wanted to be a nurse. I just think helping others and being there for someone else is very rewarding." Monica added that personal fulfillment can be a cogent force relative to job dedication. It helps to counter-balance many of the aforementioned challenges. In her words, Monica stated:

The professional fulfillment is a very important aspect of it and I just think that's the most important thing, that you really and truly enjoy your job and you love what you're doing so that you don't get up every morning and dread going into work. So that is a very big aspect of it too.... I do enjoy what I do, I love taking care of the patients....

\subsubsection{Numerous vocational options}

Another advantage found in the nursing profession is that nurses enjoy many vocational options. Mary related: "There are so many different kinds of nursing that you can do and so many different options." Since earning their nursing credential, none of the participants worked outside of the professional field (moonlighting or second career). Rather, they found ranges of options within the general nursing vocation. Ann explained:

In some ways I think the stress of maybe being a nurse or in the healthcare profession is in some ways a little easier with being a working mom, especially the nursing profession because there's so many avenues and options that you have as far as what type of nurse you want to be. You could work night shift if you want, you could work, you know, day shift, you could work evenings, you can, you know have a part time position and still get paid decently. You can work in the hospital and have those hours, you know, where you go in early and get off early, you can have the hours of mine, which are 8-4:30 Monday through Friday, you can work in a doctors office. Well, one of the reasons I went into nursing was because I knew that I could work and be a mom, that's one of the reasons why I chose nursing, because I had a bunch of different options....

Most of the nurses mentioned shift work, in varying ways, as it relates to this point. Each of the individuals was employed in a hospital setting where shifts operate in a different sync from other professional employment opportunities. The flexibility was often noted, as Lisa stated: "I think one nice thing about this 
shift is that shifts are flexible so different things might change; we do have that luxury of changing shifts somewhat to accommodate, you know, our families and what's going on at home. So that's been a positive." Similarly, Sarah compared her schedule to other 9-5 jobs: "With my schedule here I can kind of, the hours, I can kind of vary more than if I just worked a 9-5 job." In sum, the potential job variability appears to help offset some of the stressors that innately are involved with the nursing profession.

\subsubsection{Patient contact}

These floor nurses expressed enjoying the contact they are able to have with the patients. Most expressed that they do not desire to move into manager positions and, they realize that doing so would curtail the amount of personal patient contact. Susan explained: "I don't want to be management and advance.... I like the patient contact; I don't want to do the management office type stuff." Paula likewise expressed her contentment: "I don't care to be promoted; I'm quite happy where I am.... I think I limit myself and that's fine; like I said, I have no aspirations to go really any higher." Christine expressed the same sentiments and satisfaction, focusing on the here-and-now benefits she enjoys as a floor nurse: "At this point in time I have no desire to be in management and I probably never will have a desire.... But as of right now I'm just, I'm happy with what I'm doing now." Christine added the element of human personality as it relates to her own contentment as a floor nurse:

I like where I'm at, I'm not a management person; I thought at one time maybe I would want to do that, but I'm not that, I'm a more, I like being with the patients and interacting and that kind of thing. So, I'm fine where I'm at...I like dealing with the patients.

\subsubsection{Added income}

All the women in our example expressed a definite benefit of having the added income as being a significant boon. Sarah stated forthrightly: "That's why I'm here, I mean, we'd never make it if we just had to rely on the farm to uphold the house....as I said, I definitely need the income with my husband farming." When asked why she works, Ann boldly stated: "Definitely added income...," as well as Julia: "For the added income, to help pay for the bills..." Mary and Susan also add the necessity of their insurance benefits. Susan stated:

Definitely I do work for added family income. I carry the benefits in our family; the benefits that my husband have aren't very good and so I definitely have to work for that reason. And then also both of us, the bills that we accumulated in college, or mainly what I accumulated in college and then he accumulated just over the years, added up and there's no way we could do it without two incomes. 
The nurses generally described themselves as being adequately paid. There was no sentiments express of being either over-or-under paid, from their own perspectives. Whatever income they made was considered to be a staple to the overall family budget - not extra or just spending money. Susan related the principle as follows: "We couldn't survive without my income...my husband is self-employed and I have all the insurance benefits and things like that, so there's no way we could survive without my income."

\subsubsection{Medical knowledge}

Another asset in the nursing profession is the medical knowledge these women obtain and the usefulness of it, even at home. That is, they related being able to use their medical knowledge and skills during times when their own family members experience illness. Nichole explained:

I feel like as a nurse I look into things more closely as far as like if she's sick. You know, okay she's got a temperature, what's going on, or she's not eating, you know, especially with working in the nursery. I feel like I kind of tune into more of what's going on with her, trying to figure out myself then call the doctor, you know, I just kind of look at everything as a whole picture as that's concerned....

Some professions may train workers in ways that potentially could work against family enhancement. For example, family members seldom would appreciate an attorney spouse/father or mother who argued with them all the time. Nursing, in contrast, seems to have more of a complementary role for mother and professional. Rachel explained:

You're taking care of the little first aide things or the big, you know, where somebody's passing out at some event or that kind of thing. But, and then all the kids, it's like, 'well, your mom's a nurse, she can look at that.' So you kind of get a lot of those things really.

Similarly, Susan stated: "You know in the back of your head when they're sick, I mean I think all moms know that, but...there are things that you want to watch for as to what's going on, you've got the gist of it...." Mary challenged a stereotyped belief in this regard: "They say that nurses can be more paranoid sometimes, when you know a little bit more information it can be harmful. But it can also be helpful, knowing certain things about medical illnesses and things like that, it's helpful." Monica added the dynamic of feeling comfortable with childhood illnesses and being able to avoid unnecessary panic at times:

You have a basic knowledge of so much and there's many times when something's been going on with the kids or even with one of the kids' friends or something, you're a little bit more comfortable with dealing with it at home and knowing when to worry and when not to worry. 


\subsubsection{Relate to patients}

Conversely, the nurses in our sample also found that their roles as mothers have benefited their ability to relate with and care for the patients. Nichole illustrated this finding when she explained the advantage she has had in $\mathrm{OB}$, since becoming a mother herself:

With being a mom now...I can relate to the patients that are in labor because before, you know, I would take care of them and I would sympathize or, you know, have empathy for the things that they were feeling during their labor and that, but I never really knew what they were going through until I went through it myself. So I feel like I'm a better nurse and I can take care of my patients better knowing, you know, kind of what they're feeling, I know every patient's different and they go through, you know, every labor is different, but I feel like I can take care of them better now that I've experienced it and gone through now what they're going through.

I talk to patients about [her daughter] and my experiences that I had, like during my labor and my delivery and after we went home with her, because I breast fed for four months and, you know, I'll help the breast feeding moms and some of them will ask me, 'Well did you breast feed?' So I kind of share my experiences that way and, again, it's kind of, again, I can relate to what they're going through and help them out, you know, in their questions more comfortably than before because I didn't breast feed, you know, I hadn't breast fed, I hadn't had a baby.

The women similarly believe that their gender also adds a useful dynamic to their professional expertise. It was not communicated in order to be exclusive, however (i.e., male nurses also can be successful in the nursing profession, but they bring different dynamics to the job). Lisa illustrated the point as she communicated her belief that maternal instincts add a valuable dynamic to emergency room nursing experience: "That just, you know that understanding maybe of this age group or that maternal instinct makes you better able to deal with maybe what's going on with this patient or even with your kids, understanding maybe things they're going through." In sum, the roles of professional nurse and domestic mother seem to have the potential for benefiting the respective roles. The nurses in our sample believe that, generally, a complementary relationship exists between these diverse roles in life.

\subsection{The Necessities}

A careful examination of the participants' transcripts showed that most of them communicated five essentials that they believed to be necessary in order to make a nurse/working mother role to be successful. All believed that they would make an enduring career in the nursing field, but particular elements had to be in place in order for them to believe the stress/benefits balance would tip in the favor of benefits. These components included having a trustworthy and dependable 
babysitter, scheduling personal discipline, asking for help when it is needed, keeping family a priority, and earning staple nursing credentials prior to having children.

\subsubsection{Trustworthy and dependable babysitter}

Each of the women in our sample used a babysitter or some type. That is, their husbands worked outside the home and did not provide regular, daily home care for the family. Consequently, the need for suitable child care was noted as an essential for being a successful nurse at their stage of life. Mary explained how this can be a challenge:

Finding babysitters... when you or your child gets sick and, you know, trying to...having to call into work especially if you work full time...you can get into a lot of trouble if you miss too much work for those reasons.

Several of the nurses, for example Karen, advised upcoming nurse mothers to "make sure you have a good dependable babysitter in place before accepting a floor nurse position." Sarah echoed the salience of ensuring this person is reliable:

It makes it a lot easier if you're comfortable about where your children are going to be while you're gone. I know other people that have switched babysitters back and forth...monthly I have someone very reliable, actually the cousin to my husband, so kind of in the family that, you know, is at her own home and that eases my worries a lot because I don't have to be concerned at all where, that my kids are getting taken care of when I'm not there. So that would be the biggest one....

In addition to dependability, flexibility also is an essential quality for babysitters who work for full-time nurses with children. As previously mentioned, floor nurses often work unexpected overtime. Rigid schedules with babysitters can result in obvious potential problems. This dynamic affects the types and specific choices of babysitters that the nurses can hire, since they must mesh with the realities of their professional responsibilities. Susan illustrated:

If you don't have a situation like I have and you have to have a babysitter, you have to find somebody that's very flexible, as far as babysitting because, I mean, your shift might end at 3:30 but you're not always getting out of here at 3:30. So, you're going to have to find somebody's that's flexible as far as their hours and taking care....someone that you trust. I think, before my husband was self-employed that was one of the biggest things was trying to find a caregiver that you felt comfortable with and that you knew your kids were getting taken care of, before they were going to school.

\subsubsection{Keep a schedule/have "me" time}

The women in our sample indicated that they viewed personal and family scheduling to be a key for successfully combining the roles of nurse and 
homemaking. Each participant noted the necessity (not the desire, but the necessity) of having life structure and organization. We could not discern whether this phenomenon is an acquired perspective (nurture) or part of a broader personality factor that loads into characteristics of successful nurses (nature). In any event, none of the individuals in our sample described haphazard or laissez faire practices, coordinating their home and professional lives.

Although not mentioned by every participant, most also noted that they schedule time for personal relaxation or enjoyment. They used phrases such as down time or me time, but most described the need to factor stress management into the equations of their respective life schedules. As an example, when asked how she balances everything, Karen remarked:

It's called a cigarette break! If I just give, my kids are, of course mine are older, I don't have little kids at home anymore. But they know, when I walk in the door, just leave me alone; I go to my room and when I come out then we'll talk, but do not follow me in, do not nip my heels because I'll bite ya. So, it's just some down time, not very long but, you know, I just want to grab my bills and my mail, might as well just say bills because that's all I get, and just go to my room and sit there and open them up and take some me time.

She also gives the following advice to new nurses: "Take some time out for you, make sure you have you time. Make sure, because nothing else is going to work if you're grumpy and tired and unfulfilled and unhappy." There was no consensus on how long the personal time lasts and seemingly, substantial variability exists among the participants. Nonetheless, they all believe that some type of personal time is necessary for balancing the demands of a working in the nursing profession and adequately caring for their home needs. Nichole reinforced the need for regular personal experiences as follows: "I feel like I need time for myself outside of work and taking care of her... I need my time, too..." and Melanie explained how not having this time can leave an emotional cavity: "That's what I seem to miss sometimes, just alone time, and do what I want to do."

\subsubsection{Ask for help}

Most women in our sample indicated that they have learned to ask for help when they need it. This was a finding that was unexpected, but not surprising, since intuitively-it makes sense. The women did not relate this dynamic in terms of extremity or pathologically being dependent on others. Rather, they spoke in terms of realism and the need to be genuine with their friends and family. Susan stated that if she could go back and change anything she "would have been more support." Rachel noted her own perceived need for the following:

Identify a support system because you need someone that you can call on if you needed help picking up your kids or to maybe help you do some projects 
around the house, to kind of help yourself stay up with things...to not, maybe not try to do everything yourself....

Universally, the group of women spoke in terms of needs to rely on the assistance of others at times. None felt like they can do it alone-and still be successful in both domains of professional nurse and caregiver. The demands in both domains simply are too great. Ann explained how she felt her own situation had been fortunate in this regard:

Well, I'm lucky that I have a supportive husband. He's self-employed, he works at home so he's home every day when the kids get home from school and gets the dinner and starts the homework and then I just have to finish up when I get home, so...I wouldn't be able to do it without him, he's very supportive. He works at home, like I said, so he's able to be there when the kids get on and off the school bus, and get their homework started, and make supper, and sometimes when I work really late, like today I'm not getting off until 8:30 so they'll be bathed and everything will be done when I get home. So, I couldn't do it, um....I couldn't imagine, no way.

\subsubsection{Keep the family a priority}

Possibly the most important necessity expressed by the floor nurses in our study was to be careful to keep their family as a prime priority. Many of the nurses found it easy to lose focus and to spend more time on the job and seemingly not enough with their families. Nichole explained her own journey of learning to balance her professional responsibilities and home responsibilities, keeping an apt focus on the latter:

I've always wanted to be a mom, and that's kind of my main priority is to be a mom right now....Like I said, I enjoy working here, I enjoy what I do, but my main priority is [her daughter], and my husband, my family, and being a mom right now. I think I would tell them, like some of the girls told me here, as far as you know, don't get uptight about the things at home, you know, let things go. Don't worry about dishes, if there are dishes in the sink, or if the floor needs swept, you know, those things can wait until the next day. Because I always felt like I needed to have everything done, where now I've kind of eased up on it and I'm more relaxed. I don't worry about my house being spotless like it used to be before I had her... This past year has gone by so fast, I can't believe she's a year old already and um, so I mean, spend, you know, when you are at home, spend the time with her that you can and don't try to get caught up in all the house work and things like that.

The construct of ranking ordinal life choices was a frequent sentiment noted by the nurses. That is, they generally expressed desires to be the super-mom and super-nurse, but the reality is that is not always possible. In the end, most spoke in terms of having to rank what they believe to be important, then schedule according. For example, Karen explained: 
Life has mellowed me out and I found out that Dr. Spock wasn't always right, you know, and that the kids, you know, weren't going to croak because my house wasn't spotless, I've let a few things go. But I've learned to kind of prioritize...that's most important, you know, time with your kids.

Ann, Lisa, and Mary framed their own personal constucts in this domain in terms of advice they would offer younger nurses who were about to enter the life phases they currently were experiencing. Ann reminded mothers to redeem family time while it is available to them: "If the other things, things that need done, don't get done, spend the time with your kids because you don't get that time back and the messy house isn't as important as what the kids are." Lisa noted that the childrearing years are remarkably brief: "Remember what's important right now at this stage in your life or where your children are...just keep focused on what's important in your life and just how quickly your children grow up and that sort of thing." Last, Mary encouraged working nurses who are mothers to focus on daily priorities, doing their utmost with the time and energy available:

Do what you can, when you can. And it's not, I don't know, a house is a home, and you can't worry about all the aspects of having everything done...it doesn't happen. When you have kids, the house is always a mess, toys everywhere, so you just have to deal with it day by day and do the best you can and, as long as they're fed and clothed, they've got the things they need, I think that's what's important.

Monica summarized the thoughts of many participants' views when advising: "Number one, to get your priorities in line and to know what's important to you....My family is priority."

\subsubsection{Acquire education before starting a family}

As explained earlier, the nurses in our sample stated that it is difficult to advance professionally, especially relative to higher education, once nurses start families for whom they have care-responsibilities. Consequently, the women expressed the importance of obtaining nursing education before beginning a family. Rachel advised: "Get all your education before, you know, before you have your kids." Ann explained the choice she made: "I wanted to get it [education] done before I got married or before I had children. So that was a very good decision, I felt [acquiring education before marriage/children]." Karen, Monica, and Melanie all agreed that, if they could go back and make a different decision, they would have obtained their education prior to beginning their families. Karen stated: "I would, I think, get all my education first before I started a family.... I think I would've done that, first got my education first..." Monica stated: "If I could go back and make them, I would've furthered my education before I had kids. I would've gone ahead and gotten it at the time." Finally, Melanie concurred:

The only thing I would...have done differently was I would have finished all of my schooling then. Because now, unfortunately, I'm back in school and I 
wish I would've done it all then, that would be one less thing to juggle. That's the only thing I've ever felt not complete in my career, was not to have an advance degree and so um...that would be the one thing I would do... that would be the one thing probably, just to complete that, it'd be one less piece of the puzzle that I'd have to worry about now...

\subsection{Wish List}

An appraisal of the participants' interview transcripts showed two common desires the nurses shared. In particular, most of the women independently related having two desires that were not part of their current realities when working as nurses and rearing families. One was a desire to work fewer hours and the other was to be on the same work schedule as their respective children had with school and life schedules.

\subsubsection{Work less (work part time)}

As previously noted, the nurses we interviewed strongly stressed that they enjoy their daily jobs. At the same time, however, they also desired to have their current positions, but to do so with fewer scheduled hours each week. The desire is not to spend less time in the workplace, per se, but rather in order to have additional time for other aspects of their lives. Susan explained her ideal job:

Part time, that'd be good, at least have a day off through the week or something to get house work in, things done. That gets kind of put aside too, when you're working full time, house work and dishes and whatever, and laundry. So that's kind of hard. So that's usually my weekends off, doing house work and getting caught up. But part time would be good.

As previously noted, all the mothers in the present sample were full-time hospital employees. Consequently, although the desire for being part-time employees existed, none were ready to cross the threshold of taking the pay cut that would be a necessary reality involved with moving to part-time status. The nurses had previously noted in their interviews that generally the family depended on their income and the economic realities dictated that full-time nurse employment was in the mothers' foreseeable future. Nonetheless, if it were to be financially feasible - the mothers in the present sample would choose part time employment, during this phase of their season of life.

\subsubsection{Work the same hours as their children}

The second wish expressed by almost all the working-mother nurses was a desire to work the same hours that the children are in school. They would like to work during this time frame in order to be at home when their children are at home. Rachel communicated: "The ideal nursing job...would be, if you could change your hours as your kids' schedules changed." Monica related her own sentiments in this regard: 
When my kids were younger I always dreamed of being a school nurse because I thought that would be the absolute ultimate - I could work full time and be with them all the time, be at the school, whatever, work the exact hours that they were gone, the exact days, have every weekend and holiday off with them, have three months in the summer off with them. And I dreamed of that for a very long time. Of course, coming from a small school district, you don't have school nurses, so that wasn't a possibility. Now that my youngest is a senior, we have a school nurse for the first year ever, so it didn't help me out. But I always thought that would be the absolute ultimate job.

The reality is that hospital hours are not always congruent with school children's schedules. Hospital nursing schedules also seldom come with built-in flex-time. That is, the schedule is relatively rigid and a nurse cannot come into work between certain hours; when they are scheduled, nurses are expected to be at their respective hospital posts. Melanie thought creatively in this regard, and hopes hospital administrators someday will be more innovative when assigning work shifts to floor nurses:

Yeah...I...several years ago, maybe three or 4 years ago I saw this ad in the paper...and it was real interesting because they were doing, I don't know what type of turnover they were having, but they were doing some really innovative things with shifts. They were even offering hours that coincided with your children's school schedule, so like summers off, and I thought wow, that would be, to me that would be awesome. Because I think that is the hardest time for us is the summer because they're home alone all day and I don't let them go out and run around or do anything, I want them where I know they're safe. And I think that's kind of hard sometimes but, that would be the only thing would be if, like teachers, which is impossible. I mean the content of the care for the patient would be, it would be so hard, I can't imagine how that would work out, especially in a place like this. But that to me would be ideal.

\section{Discussion}

When viewing the data holistically, we drew five general principles from the perceptions shared by the nurses in our sample. First, they appear able to hold multiple-foci simultaneously. Outside of the present study, some individuals possess a relatively narrow band of life focus, seemingly to concentrate on one life domain, making it successful. This does not seem to be the case with the floor nurses in our sample. Contrariwise, they seem to look in multiple directions, such as career, family, altruism, professionalism, and the like. Giving each domain attention, and balancing them to the best of their abilities - the floor nurses we studied appear to juggle multiple aspects of their lives rather than concentrate 
primarily on only one domain. In some ways, it may be both a boon and bane. Positively, they may be relatively integrated individuals and see the multiple facets of life, how aspects fit together. This benefit also may frustrate these individuals, since they also likely can see what they are missing at times and they grasp the costs to their ordinal life choices (career versus family).

Second, floor nurses expressed a desire to have the best of all their worlds. How their children turn out is very important to them. At the same time, however, they like making excellent pay. They want personal time and quality social connections with others. There were no areas where the working mothers put up a symbolic white flag and surrendered particular quality aspects of their lives. Rather, there was a definite desire to have as much as they could obtain from each area of their lives. The stress that the working mothers expressed, to some degree, was that of their own making - part of the result imbedded with wanting all from all worlds. Most of the women communicated ranking a priority of family above career, nonetheless, when life forced them to choose.

Third, the nurses in our sample recognize the stressors in their lives. In this regard, they are relatively analytical. They showed apt skill in self-assessing which parts of their daily routines produced strain and analyzed with seeming accuracy what they might do in order to reduce life stress. Reasons for not quitting their full-time employment, despite the obvious daily pressure, include both extrinsic and intrinsic motivations. Namely, they enjoyed making the money and possessing the prestige of a medical position (extrinsic) - and also enjoyed investing their lives to the needs of others (intrinsic).

Fourth, the nurses consistently expressed a family-orientation. At least on the idealistic level, they stated that their family was a priority. They did not quit their jobs in order to prioritize their families - but philosophically they stated a desire to place family needs above their own personal desires and the needs of their patients. Further study should compare this finding with nurses in other fields, such as nurse-administrators or nurse-practitioners, assessing whether they articulate similar — or different—philosophies.

Fifth, the nurses in our sample could be called "committed" individuals. They were committed in many directions (e.g., family, work, patient needs, and the like). Going beyond the call of duty was a reported intrinsic drive for these women. Psychologically, the nurses are relatively complex individuals-but the construct of commitment appears to be a shared characteristic they all possess in common. In sum, the floor nurses' dedication showed noble and altruistic character - although the personal toll taken on their professional and family lives was not without cost. 


\section{Limitations and Future Research}

The present qualitative study can be viewed as a first step in a line of research to assess nurse/mother dynamics. Qualitative research methods are designed, in part, to generate grounded research data on which quantitative research can follow-up. In this light, quantitative data should be collected, such as surveys and research involving control groups and experimental groups of floor nurses. We believe the present results will assist quantitative researchers to develop reasonable hypotheses for testing potential moderating variables in this domain.

Our sample reflected the majority of the staff population at this particular hospital who met the purposive sampling criteria (i.e., working nurse mothers with children under 18 years old). Since the reality of our location involved only Caucasian individuals, further studies should include ample numbers of minority individuals - assessing to what degree multicultural variables might affect the present findings. Additionally, male nurses, a minority in the professional nursing field, should be included in order to assess how they manage their dual career/parental roles.

As a phenomenological research study, we relied on self-report interviews for data collection. Future studies should involve ethnographic methods, shadowing nurses both at work and also in their home milieu. Assessing to what degree nurses actually follow-through with what they stated they believe in the present study would add a salient dynamic to this research focus.

The hospital from which the sample was drawn in the present study was located in a suburban area in a medium-sized city. The study should be replicated in both urban and rural hospitals. While we believe the present findings possess apt validity for its setting, nurses working in other geographical regions may report experiences that differ from what we found in the present sample. External validity in qualitative research generally is established as studies are repeated in varying milieu, allowing researchers to connect dots and decipher patterns among various constituencies of participants [32]. We believe this particularly to be the case in the present phenomenological study.

\section{References}

[1] S. Avellar, P.J. Smock, Has the price of motherhood declined overtime? A cross-cohort comparison of the motherhood wage penalty, Journal of Marriage \& Family 65 (2003) 597-607.

[2] L.J. Hayes, A. Bonner, J. Pryor, Factors contributing to nurse job satisfaction in the acute setting: a review of recent literature, Journal of Nursing Management 18 (2010) 804-814. 
[3] B.L. Rich, J.A. LePine, E.R. Crawford, Job engagement: antecedents and effects on job performance, Academy of Management Journal 53 (2010) 617-635.

[4] J.S. Hyde, N.M. Else-Quest, H.H. Goldsmith, J.C. Biesanz, Children's temperament and behavior problems predict their employed mothers' work functioning, Child Development 75 (2004) 580-594.

[5] T. Diraz, K. Ortlepp, M. Greyling, The relationship between inter-role conflict, life satisfaction and sense of coherence in a sample of working mothers, South African Journal of Psychology 33 (2003) 191-194.

[6] P.L. Chase-Lansdale, R.A. Moffitt, B.J. Lohman, A.J. Cherlin, R.L. Coley, L.D. Pittman, J. Roff, E. Votruba-Drzal, Mothers' transitions from welfare to work and the well-being of preschooler and adolescents, Science 299 (2003) 1548-1553.

[7] E. Galinsky, Ask the children, HarperCollins, New York, 1999.

[8] P. Barglow, B.E. Vaughn, N. Molitor, Effects of maternal absence due to employment on the quality of infant-mother attachment in a low-risk sample, Child Development 58 (1987) 945-954.

[9] R. Bernal, Essays on household economics, Dissertation Abstracts International 64, 09 (2003) 3414.

[10] A. Morehead, Synchronizing time for work and family: Preliminary insights from qualitative research with mothers, Journal of Sociology 37 (2001) 355369.

[11] H.K. Spence-Laschinger, M. Leiter, A. Day, D. Gilin, Workplace empowerment, incivility, and burnout: impact on staff nurse recruitment and retention outcomes, Journal of Nursing Management 17 (2009) 302-311.

[12] R.C. Barnett, N. Marshall, Clarification of the role-quality concept, Wellesley College Center for Research on Women, Wellesley, MA, 1989.

[13] S. Letvak, Nurses as working women, AORN Journal 73 (2001) 675-682.

[14] R. Williams, Time's up, Nursing Standard 15 (2001) 14-16.

[15] A. Garey, Constructing identities as 'working mothers': Time, space, and family in a study of women hospital workers, Dissertation Abstracts International 54, 10 (1993) 3889.

[16] A. Garey, Constructing motherhood on the night shift: "Working mothers" as "stay-at-home moms", Qualitative Sociology 18 (1995) 415-438.

[17] P. Rich, Inside the black box: Revealing the process in applying a grounded theory analysis, The Qualitative Report 17 (2012) 1-23.

[18] J.A. Maxwell, Qualitative research design ( $3^{\text {rd }}$ ed.), Sage, Thousand Oaks, CA, 2012.

[19] M. Alvesson, Interpreting interviews, Sage, Thousand Oaks, CA, 2011.

[20] R.C. Bogdan, S. Biklen, Qualitative research in education, Allyn \& Bacon, Boston, 2007.

[21] J. Mason, Qualitative researching ( ${ }^{\text {nd }}$ ed.), Sage, Thousand Oaks, CA, 2002. 
[22] R.J. Chenail, Conducting qualitative data analysis: Reading line-by-line, but analyzing by meaningful qualitative units, The Qualitative Report 17 (2012) 266-269.

[23] K. Daytner, Validity in qualitative research: Application of safeguards, Paper presentation at the $19^{\text {th }}$ Annual Ethnographic and Qualitative Research in Education conference, Cedarville, OH, 2006.

[24] I. Mero-Jaffe, 'Is that what I said?' Interview transcript approval by participants: An aspect of ethics in qualitative research, International Journal of Qualitative Methods 10 (2011) 231-247.

[25] M. Mason, Sample size in saturation in Ph.D. studies using qualitative interviews, Forum: Qualitative Social Research 11, 3 (2010). Retrieved from www.qualitative-research.net/index.php/fqs/rt

[26] B.L. Rodgers, Audit trail. In L. Given (Ed.), The Sage encyclopedia of qualitative research methods (Vol. 1; pp. 43-44). Sage, Thousand Oaks, CA, 2008.

[27] B.G. Glaser, Basics of grounded theory analysis, Sociology Press, Mill Valley, CA, 1992.

[28] J.W. Creswell, Qualitative inquiry \& research design: Choosing among five approaches $\left(3^{\text {rd }}\right.$ ed.), Sage, Thousand Oaks, CA.

[29] B.G. Glaser, A.L. Strauss, The discovery of grounded theory, Aldine, Chicago, 1967.

[30] M. Raffanti, Grounded theory in educational research: Exploring the concept of 'groundedness,' In M. Firmin and P. Brewer, Ethnographic and Qualitative Research in Education Vol 2. (pp. 61-74), Cambridge Scholars Press, New Castle, UK, 2006.

[31] C. Lundberg, C.A. Young, Modified grounded theory: How defensible is it?, American Association of Behavioral and Social Sciences Journal 8 (2005) 90-98.

[32] C. Delmar, "Generalizability" as recognition: Reflections on a foundational problem in qualitative research, Qualitative Studies 1 (2010) 115-128. 